\title{
Infant-Directed Speech: Final Syllable Lengthening And Rate Of Speech
}

\author{
Church, Robyn' ${ }^{1}$ Bernhardt, Barbara ${ }^{2}$, Pichora-Fuller, Kathy ${ }^{3}$, and Shi, Rushen ${ }^{4}$ \\ ${ }^{1}$ BC Family Hearing Resource Centre, 15220-92nd Avenue, Surrey, British Columbia V3R 2T8 \\ ${ }^{2}$ School of Audiology \& Speech Sciences, 5804 Fairview Avenue, University of British Columbia, Vancouver, BC, V6T 1 Z3 \\ ${ }^{3}$ University of Toronto at Mississauga, Department of Psychology, 3359 Mississauga Rd N, Mississauga, Ontario L5L 1C6 \\ ${ }^{4}$ Dept of Linguistics, Dept of Psychology, Université du Québec à Montréal, 3150 rue Jean-Brillant, Montréal, PQ, H3T 1N8
}

\begin{abstract}
The present study compared infant-directed speech (IDS) and adult-directed speech (ADS) for two mothers of preverbal infants. Each mother participated in two recording sessions, one with her child, and one with an adult friend. The primary objective of the study was to determine the influence of exaggerated utterancefinal syllable lengthening on the rate of IDS. A secondary objective was to compare the rate of speech read to infants with the rate of spontaneous IDS. The results showed an overall slower rate of speech in IDS to preverbal infants compared with ADS, replicating previous research. However, when the utterance-final syllable was excluded from the calculation of rate, the rate of speech in spontaneous IDS and ADS did not differ significantly. Speech was read to infants at a slower rate than spontaneous IDS. Implications for future research are suggested.
\end{abstract}

\section{SOMMAIRE}

La présente étude a comparé les discours de deux mères dirigés soit vers leur enfant d'âge préverbal soit vers un adulte. Chacune des mères a participé à deux sessions d'enregistrement, dont une avec son enfant et une seconde avec une amie adulte. L'étude avait comme objectif principal de déterminer l'influence de l'allongement exagéré des syllabes en position finale d'énoncés sur la vitesse du discours dirigés vers l'enfant. L'objectif secondaire était de comparer la vitesse des discours lus aux enfants avec celle des discours spontanés dirigés vers l'enfant. Les résultats ont démontré une vitesse globale plus lente des discours dirigés vers les enfants préverbaux comparativement aux discours dirigés vers unadulte, en répliquant des recherches antérieures. Cependant, lorsque les syllabes en position finale d'énoncés étaient exclues des calculs, la vitesse des discours spontanés dirigés vers l'enfant ou vers l'adulte ne différait pas de façon significative. Les discours étaient lus aux enfants à une vitesse plus lente que les discours spontanés dirigés vers l'enfant.

\section{INTRODUCTION}

Adults often modify their speech when talking to infants, a speech style which researchers have referred to as 'motherese' (Garnica, 1977; Fernald \& Simon, 1984; Grieser \& Kuhl, 1988; Fernald \& Mazzie, 1991). The current paper focuses on one characteristic of 'motherese,' the rate of infant-directed speech (IDS) in comparison with adult-directed speech (ADS). Research has shown rate of speech to be slower in IDS than ADS (e.g. Swanson et al., 1992, Albin \& Echols, 1996, Bernstein Ratner, 1985, 1996). In Bernstein Ratner's (1985) study, mothers' overall spontaneous speech rate to their children was slower in IDS compared with ADS by almost 25\% (184 wpm for ADS, compared with $138 \mathrm{wpm}$ for IDS), although individual segment durations were not different. Comparing speech in read and spoken texts, Morgan (1986) stated that mothers' rate of speech was slower in spontaneous speech than read text, although presented no measurements. In recent studies by Shute \& Wheldall $(1999,2001)$, fathers and grandmothers took longer to read a passage to children than to adults, although speaking rate was not specifically determined nor compared with that of spontaneous speech.

The slower rate of IDS has often been attributed to the overall lengthening of stressed syllables, whatever their utterance position (Swanson, Leonard \& Gandour, 1992; Albin \& Echols, 1996; Bernstein Ratner, 1996). However, there could be another explanation for the slower rate of speech of IDS. Utterances are consistently shorter in IDS than in ADS (Fernald \& Simon, 1984) and the length of the final word tends to be exaggerated (Albin \& Echols, 1996; Bernstein Ratner, 1996). The oft-noted slower rate of IDS may simply reflect the presence of extra-long final syllables 
in very short utterances. As suggested early on by Oller (1973), any study concerned with speaking rate needs to take final-syllable lengthening into account. The current study set out to compare ADS and IDS in terms of the utterance-final syllable and the remainder of the utterance, in order to determine the particular impact of the exaggerated final syllable on speaking rate. The following discussion outlines previous findings on ADS and IDS with respect to speaking rate and phrase-final lengthening and implications for language acquisition.

In English ADS, prosodic changes such as pausing, pitch changes, and vowel lengthening have been shown to occur at utterance boundaries and even at within-utterance phrase boundaries (Cooper \& Paccia-Cooper, 1980). Syllables that end utterances, clauses, and phrases tend to be lengthened relative to syllables elsewhere in utterances (Cooper \& Sorensen, 1981). As noted above, several researchers have found phrase-final lengthening to be more exaggerated in IDS compared with ADS (Morgan, 1986; Swanson et al., 1992; Albin \& Echols, 1996; Bernstein Ratner, 1996).

Different explanations have been put forward for the exaggeration of various prosodic cues in IDS. One hypothesis ('prosodic bootstrapping') suggests that exaggerated prosodic cues may provide language learners with segmentation information that can serve as a basis for syntactic category development (Morgan, 1986; Kemler Nelson, Hirsh-Pasek, Jusczyk, \& Wright Cassidy, 1989; Gerken, Jusczyk \& Mandel, 1994; Fernald \& McRoberts, 1996; Shi, Morgan \& Allopenna, 1998). Because long pauses in IDS are nearly always at the ends of utterances (Broen, 1972; Fernald \& Simon, 1984), the exaggerated lengthening of the pre-pausal syllable may serve as an accentuated cue to grammatical boundaries. Another hypothesis suggests that the exaggerated prosodic cues may serve as an implicit word teaching strategy. Woodward and Aslin (1990) hypothesized that mothers have tacit knowledge that infants can better attend to and remember words placed in utterance-final position. In word teaching studies by Woodward and Aslin (1990) and Fernald and Mazzie (1991), mothers consistently placed target words in utterance-final position in IDS, whereas in ADS, positioning of target words was variable.

Currently, it is unclear whether exaggerated pre-pausal lengthening in IDS serves as a cue to grammatical phrase segmentation or to word segmentation or both. Differences in design of the various studies have perhaps contributed to the alternative findings and explanations. The following section outlines results of pertinent studies in terms of the various ages of infant addressees for both spontaneous and read speech samples, and in terms of the different phrasal positions of the measured words or syllables. Various interpretations of the impact of exaggerated prosodic cues on rate of speech in IDS are discussed.

Studies of spontaneous English IDS to preverbal infants have consistently shown exaggerated utterance-final lengthening. For example, in Bernstein Ratner's (1986) study of IDS to preverbal children aged 9 to 13 months, utterance-final vowels in IDS were almost twice as long as those in ADS. Albin and Echols (1996) observed exaggerated utterance-final lengthening in spontaneous IDS to young preverbal infants (6 to 9 months), even for unstressed utterance-final syllables.

Results have differed across studies of older children, however. These differences may reflect the type of speech samples used. Bernstein Ratner $(1985,1986)$ found a general decrease in utterance-final lengthening in spontaneous IDS from the one-word to the two-word phase of development; by the time children combined words, utterance-final lengthening in IDS was much more similar to that observed in ADS. These findings contrast with those of Morgan (1986) and Swanson et al. (1992), who found exaggerated utterance-final lengthening in IDS to older verbal toddlers and preschoolers when mothers were reading prepared texts.

Results regarding exaggerated lengthening in IDS compared with ADS have also diverged regarding position of stressed syllables in the utterance, and again may reflect type of speech sample used. In Bernstein Ratner's (1985, 1986) studies using spontaneous speech, there was no main effect of addressee on the duration of utterance-medial. phrase-final, stressed syllable durations. Durations of utterance-medial phrase-final syllables remained almost constant across all groups of child and adult listeners. When using prepared read texts, however, Swanson et al. (1992) found exaggerated lengthening in utterance-medial, phrasefinal position. In their study, the increase in phrase-final lengthening in IDS was, on average, $11.8 \mathrm{~ms}$ longer than phrase-final lengthening in ADS. Using prepared read texts, Morgan also reported that phrase-final target word durations were significantly longer in IDS than in ADS. However, only three of the seven phrase-final target words in the mothers' IDS showed exaggerated lengthening in IDS as compared with ADS.

In summary, the results outlined above have differed depending on the age of the addressee, phrasal position, and the type of speech sample (read versus spontaneous). In studies with younger infants, exaggerated utterance-final lengthening has been found in spontaneous IDS. With older children, only the studies using read texts have shown exaggerated lengthening of stressed syllables, independent of phrasal position. Generally, rate of speech appears slower in IDS when compared with ADS, although rate in read texts may differ from rate in spontaneous speech. The source of the slower rate of IDS in spontaneous speech is unclear.

The present study was constructed to address questions arising from the literature regarding the interaction of rate and utterance-final lengthening in IDS to preverbal infants, and the effect of speech sample type (read versus 
spontaneous speech). The first objective was to determine whether and to what extent the slower rate of speech in IDS might be a result of exaggerated utterance-final syllable lengthening. The second objective was to determine whether the rate of speech read to infants was slower or faster than that of spontaneous IDS. We chose to examine speech directed to preverbal infants, because infants even as young as 6 to 9 months have shown perceptual sensitivity to utterance-boundary pauses and pre-boundary syllable lengthening, particularly in IDS (e.g., Kemler Nelson, et al., 1989).

\section{METHOD}

\section{Participants}

Two mothers, their infants, and two adult female friends participated in the study. Small $\underline{\underline{n}}$ studies may limit the generalizability of results but do allow for larger data samples and more in-depth analyses of individual data. The adults were speakers of standard Canadian English, and were both middle-class Caucasians in their early 30's. The infants were firstborn preverbal males, aged 8.5 months and 11 months.

Each mother participated in two 45-minute audio recording sessions, the first with her child, and the second with her friend. The recording sessions with the motherchild dyads were made in the mother's home an hour after the infant had awoken. To provide some consistency between the conversational contexts, the investigator brought children's toys and books to the sessions. Each mother was instructed to interact with her child as naturally as possible, and to read the books to her child at some convenient point. The recording sessions with the adult female friend were held at the home of the friend without any children present. The adults were instructed to have a natural conversation. The mothers were instructed to read the same children's books to the friend at some point in the conversation and to do so as they might to an adult. For all four recordings the investigator was nearby but not in the same room. Audio recordings were made using a Marantz tape recorder model number PMD420, a VHF wireless receiver and transmitter, and a Lavalier microphone that was clipped to the mother's collar.

\section{Transcription and data selection procedures}

For the current study, an utterance was defined acoustically as a section of speech bounded by pauses greater than $300 \mathrm{~ms}$ (following Jaffe \& Feldstein, 1970, and Fernald \& Simon, 1984). Because the final syllable of many longer English words is short and unstressed, only utterances ending in monosyllabic stressed words were used, in order to be able to observe utterance-final lengthening more easily (following Bernstein Ratner, 1985, 1986; Morgan, 1986; Swanson et al., 1992). A total of 413 utterances ending in stressed monosyllabic words were identified for analysis, and coded as spontaneous or read. The first and second authors made independent orthographic transcriptions of the utterances, and agreed on over $99 \%$ of the words. Table 1 shows a breakdown of the number of utterances per participant, addressee, and condition.

From the audiotapes each selected utterance was digitized at $22.050 \mathrm{kHz}$ (16 bits) using the SoundEdit 16 version 2 program (1996) on a Macintosh computer. Individual soundfiles (AAIF) were created for each utterance. For each soundfile, Macquirer version 6.0 (2000) was used to produce a spectrogram of the waveform, with a bandwidth of $344 \mathrm{~Hz}$ and a frequency range of $6000 \mathrm{~Hz}$. Because an utterance was defined acoustically as a section of speech bound by pauses greater than $300 \mathrm{~ms}$, there were no between-utterance segmentation difficulties.

Table 1. Number of utterances per participant, addressee, and

\begin{tabular}{|c|c|c|c|}
\hline Participant & Addressee & $\begin{array}{c}\text { Total } \\
\text { utterances } \\
\text { per session }\end{array}$ & $\begin{array}{c}\text { Coded utterances } \\
\text { per session }\end{array}$ \\
\hline 1 & Infant & 480 & $\begin{array}{c}94 \text { spontaneous } \\
22 \text { read }\end{array}$ \\
\hline 1 & Adult & 430 & 75 spontaneous \\
16 read
\end{tabular}

\section{Measurements of duration}

Two measurements of duration (in milliseconds) were made for each selected utterance: the total utterance time and the duration of the final stressed syllable. Segmentation decisions for durational measurements were made using the waveform and the spectrogram, according to the following criteria. Over $90 \%$ of the utterances began with a voiced segment; in these cases, onset of phonation was a reliable cue to the beginning of the utterance. For the few utterances with initial voiceless fricatives (e.g. she, should, shall, so, see), frication noise on both the waveform and the spectrogram was taken to mark the beginning point. The cues for the onsets of voiceless stops could not be reliably determined in the data and therefore the onset of vowel phonation was used as the beginning point.

Determining the end of the utterance proved more difficult. For fricatives, the spectrogram was used to determine cessation of frication. To determine the terminal boundary of a stop, the first step was to establish the presence or absence of a release burst by identifying 
frication on the waveform and the spectrogram. The cessation of frication on the spectrogram was taken as the indication of the terminal boundary for voiced stops with a voiced release (e.g. crib, ride, dog, etc.) and voiceless stops with a voiceless release burst (e.g. flap, boat, think, etc.). For unreleased voiceless stops in which there was no frication, the point of closure for the stop was used to mark the terminal boundary for the syllable (e.g. night, milk, etc.). The cessation of pitch pulses on the waveform was taken as the indication of the terminal boundary for unreleased voiced stops (e.g. bed, egg, etc.) and other voiced segments (except for voiced fricatives).

The delineation of successive syllables was challenging because of co-articulatory effects between segments. In many instances the transitions between segments occurring at syllable boundaries had overlapping cues, making segmentation difficult. Criteria for syllable segmentation were derived from Fant (1962), in which phonemes are broken down into successive sound segments. The beginning point of co-articulation was consistently clearer than the ending point, especially for formant transitions, and was thus considered the syllable boundary. Where either the same segment or two acoustically indistinguishable segments occurred at syllable boundaries (e.g. her-ROOM, that-can, etc.), the total time of the two segments was halved, and that halfway point delineated as the syllable boundary.

Ten utterances were selected randomly from each audiotape and measured three times each over a three-month period by the first author. The mean error for utterance onsets was $3.4 \mathrm{~ms}$ (range $=0-6 \mathrm{~ms}$ ), for unstressed syllables it was $9.7 \mathrm{~ms}$ (range $=0-19 \mathrm{~ms}$ ), and for utterance endings it was $20.6 \mathrm{~ms}$ (range $=3-37 \mathrm{~ms}$ ). For 10 randomly selected utterances, the fourth author confirmed consistent use of the above procedures through independent measurement. The first author consulted with the fourth author if there was any doubt about measurement decisions; the measurement agreed upon by both coders was taken in these cases.

\section{Calculation of rate}

Rate of speech was calculated in syllables per second. Pauses over $300 \mathrm{~ms}$ were excluded following studies such as Fernald \& Simon (1984). Calculating rate in this way eliminated possible confounding differences in length and frequency of between-utterance pauses in IDS compared with ADS. Two measurements were made. For Rate 1, the number of syllables for each utterance was divided by the utterance's total duration. In order to determine the influence of the exaggerated utterance-final syllable on rate, a second calculation was made excluding the final stressed syllable. Rate 2 was computed by dividing the total number of syllables minus one in each utterance by the total utterance duration minus the final syllable duration.

\section{RESULTS}

Results are given for (a) durations of stressed utterancefinal monosyllables in ADS and IDS, and (b) speech rates in ADS and IDS, including and excluding the utterance-final syllables. Comparisons are made for spontaneous and read text samples.

\section{Duration of utterance-final syllables in ADS and IDS}

Table 2 lists the mean durations and standard deviations (in milliseconds) of the utterance-final stressed syllables for each participant.

In spontaneous ADS, the duration of the utterance-final stressed syllable was similar for both participants. It was longer for each participant in IDS compared to ADS, although Participant 1 showed greater utterance-final syllable lengthening in IDS than did Participant 2. The ADS-IDS difference was significant for both participants: $F(1,167)=79.99, p<0.01$ for Participant $1 ; F(1,168)=23.66$, $p<0.01$ for Participant 2 (2 one-way ANOVAs).

Table 2. Mean durations of the final stressed syllables for each

\begin{tabular}{|c|c|c|c|c|}
\hline Participant & $\begin{array}{l}\text { Addressee } \\
\text { Condition }\end{array}$ & $\begin{array}{c}\# \\
\text { of utterances }\end{array}$ & $\begin{array}{l}\text { Mean syllable } \\
\text { duration (ms) }\end{array}$ & S.D. (ms) \\
\hline \multirow[t]{4}{*}{1} & ADS-S & 75 & 386.3 & 112.9 \\
\hline & ADS-R & 16 & 459.0 & 124.8 \\
\hline & IDS-S & 94 & 586.1 & 165.1 \\
\hline & IDS-R & 22 & 631.1 & 180.4 \\
\hline \multirow[t]{4}{*}{2} & ADS-S & 79 & 385.9 & 115.7 \\
\hline & ADS-R & 16 & 502.3 & 91.3 \\
\hline & IDS-S & 91 & 489.1 & 154.7 \\
\hline & IDS-R & 20 & 636.4 & 139.9 \\
\hline
\end{tabular}

Note. ADS = adult-directed speech; IDS = infant-directed speech; $\mathrm{S}=$ spontaneous; $\mathrm{R}=$ read texts.

\section{Rate of speech}

Two different calculations of speech rate were made for both spontaneous and read speech across addressee conditions as described above. Spontaneous speech rates were slower in IDS than in ADS for both participants. (See Table 3 and Figure 1.)

The Rate 1 differences between spontaneous IDS and ADS were significant for both participants: $F(1,167)=$ 
45.31, $p<0.01$ for Participant 1; $F(1,168)=11.93, p<0.01$ for Participant 2 (two one-way ANOVAs). The Rate 2 differences between spontaneous IDS and ADS (excluding the duration of the final syllable) were not significant for either participant: $F(1,167)=1.48, p=0.23$ for Participant 1 ; $F(1,168)=0.54, p=0.46$ (two one-way ANOVAs).

Table 3. Mean rates in syllables/sec for spontaneous and read speech with the utterance-final syllable included and excluded.

\begin{tabular}{|c|c|c|c|c|c|}
\hline Participant & $\begin{array}{l}\text { Addressee } \\
\text { condition }\end{array}$ & Rate $^{a}$ & $\begin{array}{c}\text { \# of } \\
\text { utterances }\end{array}$ & $\begin{array}{l}\text { Mean rate } \\
\text { (syllables/ } \\
\text { second) }\end{array}$ & S.D. \\
\hline \multirow[t]{6}{*}{1} & ADS-S & 1 & 75 & 5.30 & 1.28 \\
\hline & ADS-S & 2 & 75 & 6.37 & 1.81 \\
\hline & IDS-S & 1 & 94 & 4.14 & 0.94 \\
\hline & IDS-S & 2 & 94 & 6.03 & 1.85 \\
\hline & IDS-R & 1 & 22 & 3.31 & 0.79 \\
\hline & IDS-R & 2 & 22 & 4.91 & 1.79 \\
\hline \multirow[t]{6}{*}{2} & ADS-S & 1 & 79 & 5.92 & 0.71 \\
\hline & ADS-S & 2 & 79 & 7.63 & 1.30 \\
\hline & IDS-S & 1 & 91 & 5.25 & 1.29 \\
\hline & IDS-S & 2 & 91 & 7.87 & 2.06 \\
\hline & IDS-R & 1 & 20 & 3.47 & 0.71 \\
\hline & IDS-R & 2 & 20 & 4.87 & 1.30 \\
\hline
\end{tabular}

Note. ADS $=$ adult-directed speech; IDS = infant-directed speech; $\mathrm{S}=$ spontaneous; $\mathrm{R}=$ read texts

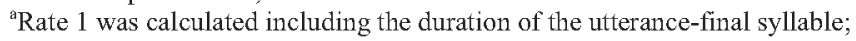
rate 2 was calculated excluding the duration of the final syllable.

These results differed from rate of speech in read texts. The rate of speech that was read to the infants was slower than the rate of spontaneous IDS for both participants. This was the case in both the Rate 1 and 2 calculations (Table 3): Rate 1 -- $F(1,114)=14.47, p<0.0005$ for Participant 1 , and $F(1,109)=35.81, p<0.0005$ for Participant 2 ; Rate 2 -$F(1,114)=6.57, \quad p<0.01 \quad$ for Participant 1 and $F(1,109)=38.71, \quad p<0.01$ for Participant 2 (one-way ANOVAs).

\section{DISCUSSION}

The results of the present study for IDS showed exaggerated lengthening of the utterance-final syllable and an overall slower rate of speech in IDS compared to ADS. These two results replicate previous research findings with preverbal infants, but using both spontaneous and read texts.

The first objective was to determine whether and to what extent the slower rate of speech in IDS might be a result of exaggerated utterance-final syllable lengthening. The present study indicates that the slower rate of IDS appears to be a product of extra-long final syllables occurring in very short utterances. When the final syllable was excluded from the calculation, the rate of spontaneous speech for the earlier portion of the IDS utterances was not significantly different from the rate of speech in ADS. The articulation rate of the syllables in utterances preceding the final syllable was similar in IDS and ADS.

The second objective of the current study was to determine whether the rate of spontaneous and read IDS might differ. For the two mothers, read IDS was slower than spontaneous IDS and in this case the utterance-final syllable was not solely responsible for the slower rate of speech. Comparisons with previous studies are outlined below, and implications for future research suggested.

Duration of utterance-final syllable $v$ s remainder of utterance

The mean utterance-final syllable duration was significantly longer in IDS than in ADS for both participants in the present study. These results generally replicate earlier studies on utterance-final syllables in IDS with preverbal infants (Bernstein Ratner, 1986; Albin \& Echols, 1996). However, the rate of articulation of the syllables preceding the final syllable was found to be similar in spontaneous IDS and ADS, a finding which has not been previously reported. Bernstein Ratner (1985) had noted that the 'global rate adjustment [in IDS] did not translate directly into longer segmental durations' (Bernstein Ratner, 1985: 262) but offered no explanation for the overall slower rate. The present study suggests that the overall slower rate is in large part due to the occurrence of extra- long final syllables in typically short utterances. This differs from previous interpretations, which suggest that the slower rate of IDS was due to the overall lengthening of stressed syllables regardless of phrasal position (Morgan, 1986; Swanson et al., 1992; Albin \& Echols, 1996; Bernstein Ratner, 1996).

\section{'Prosodic bootstrapping' versus word teaching strategies?}

The advocates of the prosodic bootstrapping hypothesis suggest that the more extreme pre-pausal lengthening in IDS compared to ADS may serve as an accentuated acoustic marker of utterance boundaries (1984), and serve as a cue to grammatical categories. An alternative hypothesis suggests that pre-pausal lengthening may be used to attract the 
infants' attention as a way to teach new words. In this study, it was only the utterance-final syllable in spontaneous IDS that showed exaggerated lengthening. It is not clear how a syntactic category could be inferred from a single extra-long syllable, especially when the rest of the utterance is articulated at the same rate as an utterance in ADS. Considering the preverbal stage of the infants in this study, the exaggerated lengthening may have served as a more general attentional cue and/or as a specific grammatical bootstrapping cue. More research is needed to compare spontaneous IDS to infants at early versus later developmental phases, and to relate it to actual language perception, comprehension and production..

\section{Rate of speech in spontaneous IDS and the issue of pauses}

Earlier studies from the 1970 s comparing rate of speech in IDS and ADS were calculated in words per minute. Between-utterance pauses were not excluded from these calculations of rate. However, the between-utterance pauses would account for some of the slower rate of speech in IDS compared to ADS because in IDS pauses are longer and more frequent (Garnica, 1977; Fernald \& Simon, 1984; Grieser \& Kuh1, 1988; Fernald \& Mazzie, 1991). Studies in the $1980 \mathrm{~s}$, as in the present study, calculated the rate of speech in syllables per second excluding pauses over $300 \mathrm{~ms}$ (e.g. Fernald \& Simon, 1984). This calculation is a more accurate depiction of the rate of articulation because the confounding difference in length and frequency of betweenutterance pauses in IDS compared to ADS has been eliminated. However, differences due to length and frequency of the utterance-final syllable in IDS compared to ADS are still confounded. Perhaps a more accurate portrayal of the rate of articulation in IDS compared to ADS would involve a calculation of rate in which both the betweenutterance pauses and the duration of the final syllable are excluded, a possibility for future research.

Read text versus spontaneous speech

Morgan commented that IDS samples from prepared read texts appeared to have a faster rate of speech than spontaneous IDS, although he provided no instrumental measurements to support that claim (1986: 121). In the current study, acoustical measures revealed that read text was slower overall than spontaneous speech in IDS. Other methodological differences between the current study and that of Morgan (1986) may also have led to different results, for example, age of child addressee, number of participants, and type of read text. The children in Morgan's (1986) study were verbal and older than the preverbal children in this study ( 2 and 4 years of age compared with $81 / 2$ - and 11 months of age). The results of the present study are more in line with those of Bernstein Ratner (1985), who found exaggerated utterance-final lengthening in spontaneous IDS to preverbal infants but not to older verbal toddlers. In terms of number of participants, the present study only included two mothers, compared with 34 in the Morgan (1986) study.
The particular adults in this study may have had slower oral reading rates. The type of read text may also have been relevant. Both studies used stories, but in the Morgan study (1986) experimentally designed sentences were embedded within the story. In the current study, the books were typical children's books.

For read texts, even when the utterance-final syllable was excluded from rate calculations, speech rate in IDS remained significantly slower than spontaneous IDS. Thus, syllables preceding the utterance-final syllable were also lengthened. The slower rate of the syllables preceding the final syllable in the read speech can be attributed to longer segmental durations in read IDS compared with spontaneous IDS. These results are consistent with the observed overall exaggerated lengthening of stressed syllables (phrase-final and non-phrase-final) in studies of read IDS (Morgan, 1986; Swanson et al., 1992). These researchers proposed that the observed vowel lengthening was due to the addressee condition; i.e., that the speech was IDS versus ADS. Morgan stated: 'Thus, as expected, the slower speech rate evident in child-directed speech is due in part to the lengthening of at least stressed vowels in content words' (1986: 118). The syllable-level analysis of the utterances in the present study does not examine the specific lengths of particular types of segments, and thus supports only a syllable-level interpretation of data, with evidence of syllable lengthening in utterance-medial content words but only in speech that is read to infants and not in spontaneous IDS. Both Morgan (1986) and Swanson et al. (1992) acknowledged that the read speech in their studies might not be fully representative of spontaneous speech. However, neither discussed the possibility that the type of speech (read vs spontaneous) might be the source of the differences in utterance-medial vowel durations and the related differences in rate that they previously observed. Further research comparing speech rates of read and spontaneous IDS and $\mathrm{ADS}$ is required to resolve this apparent confound. In addition, these findings could also have implications for infant word recognition research, which typically use read texts as experimental stimuli. No study has used spontaneous IDS as stimuli. It might be necessary for future infant speech segmentation research to focus on infants' word segmentation for spontaneous IDS in comparison with read IDS.

\section{CONCLUSIONS}

The present study showed exaggerated lengthening of the utterance-final syllable and an overall slower rate of speech in IDS compared to ADS. The utterance-final lengthening was solely responsible for the slower rate of spontaneous IDS compared with ADS, but was only partially responsible for the slower rate of read text in IDS compared to spontaneous IDS. Previous researchers have suggested that the exaggerated prosodic cues of IDS 
accentuate syntactic boundaries and are indirect evidence for prosodic bootstrapping. However, these suggestions have been based primarily on observed acoustic properties of mother's reading of prepared texts to verbal children (Morgan, 1986; Swanson et al., 1992). Research using spontaneous speech has found less exaggerated utterancefinal lengthening in speech to children at the one-word phase and negligible exaggeration in speech to children at the two-word phase (Bernstein Ratner, 1986) This study. like others to preverbal infants, found exaggerated utterance-final syllable lengthening in spontaneous IDS to preverbal infants, but no lengthening of non-utterance-final syllables, suggesting that the duration cue for utterance boundary is indeed more reliable in ID than AD spontaneous speech. Further cross-linguistic research is needed with children at different ages, and with both spontaneous and prepared text samples, to resolve some of the conflicts in the literature. In addition, in order to understand the function of the various exaggerated cues of IDS, studies need to include data from the children in the mother-child dyads.

\section{ACKNOWLEDGMENTS}

This work was supported by funding from NSERC, SSHRC and the UBC Peter Wall Institute for Advanced Studies Major Thematic grant on 'Acoustic Ecology'. We would like to thank Trudy Adams, Bryan Gick, and Joseph Stemberger, as well as the participants. This paper is based on the Master's thesis of Robyn Church.

\section{REFERENCES}

Albin, D. D. \& Echols, C. H. (1996). Stressed and word-final syllables in infant-directed speech. Infant Behaviour and Development 19, 401-418.

Bernstein Ratner, N. (1985). Dissociation between vowel durations and formant frequency characteristics. Journal of Speech and Hearing Research 28, 255-264.

Bernstein Ratner, N. (1986). Durational cues which mark clause boundaries in mother-child speech. Journal of Phonetics 14, 303-309.

Bernstein Ratner, N. (1996). From "signal to syntax": But what is the nature of the signal? In J. L. Morgan, and K. Demuth (eds.), Signal to syntax: Bootstrapping from speech to grammar in early acquisition. Mahwah, NJ: Lawrence Erlbaum Associates, pp. 135-150.

Broen, P. A. (1972). The verbal environment of the languagelearning child. Monograph of American Speech and Hearing Association 17, December, 1972.

Cooper, W., \& Paccia-Cooper, J. (1980). Syntax and speech. Cambridge: Harvard University Press. Cooper, W. E., \& Sorensen, J. M. (1981). Fundamental frequency in sentence production. New York: Springer - Verlag.

Fant, C. G. M. (1962). Descriptive analysis of the acoustic aspects of speech. Logos 5,3-17.

Fernald, A., \& Mazzie, C. (1991). Prosody and focus in speech to infants and adults. Developmental Psychology 27, 209-221.

Fernald, A., \& McRoberts, G. (1996). Prosodic bootstrapping: a critical analysis of the argument and the evidence. In J. L. Morgan, and K. Demuth (eds.), Signal to syntax: Bootstrapping from speech to grammar in early acquisition. Mahwah, NJ: Lawrence Erlbaum Associates, pp. 126-143.

Fernald, A., \& Simon, T. (1984). Expanded intonation contours in mother's speech to newborns. Developmental Psychology 20 , 104-113.

Garnica, O. (1977). Some prosodic and paralinguistic features of speech to young children. In C.E. Snow and C. A. Ferguson (eds.), Talking to children: Language input and acquisition. Cambridge, England: Cambridge University Press.

Gerken, L., Jusczyk, P. W., \& Mandel, D. R. (1994). When prosody fails to cue syntactic structure: Nine-month-olds' sensitivity to phonological vs. syntactic phrases. Cognition 51, 237-265.

Grieser, D. L., \& Kuhl, P. K. (1988). Maternal speech to infants in a tonal language: Support for universal prosodic features in motherese. Developmental Psychology 24, 14-20.

Jaffe, J., \& Feldstein, S. (1970). Rhythms of dialogue. New York, NY: Academic Press.

Kemler Nelson, D., Hirsh-Pasek, K., Jusczyk, P.W. \& Wright Cassidy, K. (1989). How the prosodic cues in motherese might assist language learning. Journal of Child Language 16, 55-68.

Macquirer 6.0, 2000. (Los Angeles, CA: Scicon R \& D., Inc.).

Morgan, J. L. (1986). From simple input to complex grammar. Cambridge, MA: MIT Press.

Oller, D. K. (1973). The effect of position in utterance on speech segment duration in English. Journal of the Acoustical Society of America 54, 1235-1246.

Shi, R., Morgan, J., \& Allopenna, P. (1998). Phonological and acoustic bases for earliest grammatical category assignment: A cross-linguistic perspective. Journal of ChildLlanguage 25, 169-201.

Shute, B. \& Wheldall, K. (1999). Fundamental frequency and temporal modifications in the speech British fathers to their children. Educational Psychology, 19, 221-233.

Shute, B. \& Wheldall, K. (2001). How do grandmothers speak to their grandchildren? Fundamental frequency and temporal modifications in the speech of British grandmothers to their grandchildren. Educational Psychology, 21, 493-503.

SoundEdit 16 (2) (1996). (San Francisco, CA: Macromedia).

Swanson, L., Leonard, L., \& Gandour, J. (1992). Vowel duration in mothers' speech to young children. Journal of Speech and Hearing Research 35, 617-625.

Woodward, J. Z. \& Aslin, R. N. (1990). Segmentation cues in maternal speech to infants. Paper presented at the International Conference on Infant Studies, Montreal, April, 1990. 


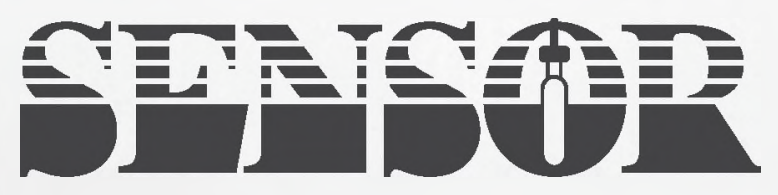

$$
\begin{aligned}
& \text { Acoustic } \\
& \text { Transducers, } \\
& \text { Hydrophones } \\
& \text { and } \\
& \text { " P'ezoelectris } \\
& \text { i Materias }
\end{aligned}
$$

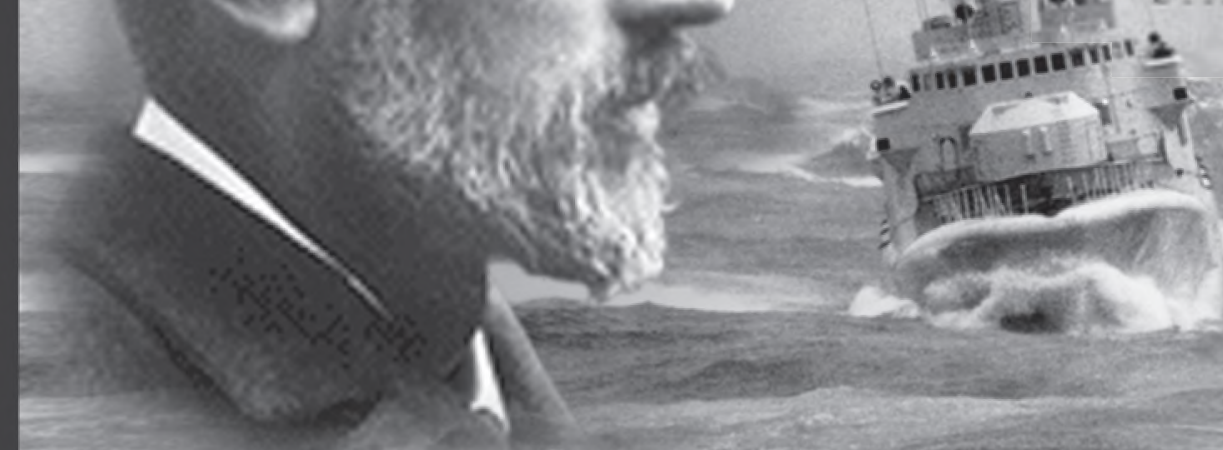

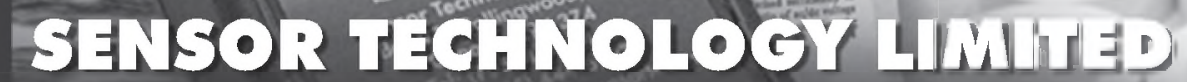
PO Box 97, Collingwood, Ontario, Canada L9Y $3 Z 4$ www.sensortech.ca email: techsupport@sensortech.ca 2006 catalogue now available 